Rola K. 2012. Taxonomy and distribution of Allium ursinum (Liliaceae) in Poland and adjacent countries. - Biologia 67(6): 1080-1087.

RozPorZĄDZENIE Ministra Środowiska z dnia 9 października 2014 r. w sprawie ochrony gatunkowej roślin (Dz. U. 2014 r., poz. 1409).

Ustawa z dnia 16 kwietnia 2004 r. o ochronie przyrody (Dz. U. 2020 r., poz. 55).

ZAJĄC A. 1978. Założenia metodyczne „Atlasu rozmieszczenia roślin naczyniowych w Polsce”. - Wiadomości Botaniczne 22(3): 145-155.

ZAJĄC A. \& ZAJĄC M. (red.). 2019. Atlas rozmieszczenia roślin naczyniowych w Polsce - dodatek. s. 306. Instytut Botaniki Uniwersytetu Jagiellońskiego, Kraków.

ZAJĄC M. \& ZAJĄC A. 2009. Elementy geograficzne rodzimej flory Polski. s. 94. Nakładem Pracowni Chorologii Komputerowej Instytutu Botaniki Uniwersytetu Jagiellońskiego, Kraków.

ZARZYCKI K. \& Szeląg Z. 2006. Czerwona lista roślin naczyniowych w Polsce. - W: Z. MireK, K. ZarzyCKI, W. Wojewoda \& Z. Szeląg (red.). Czerwona lista roślin i grzybów Polski, s. 11-20. Instytut Botaniki im. W. Szafera, Polska Akademia Nauk, Kraków.

Zarzycki K., Trzcińska-Tacik H., Różański W., Szeląg Z., Woeek J. \& Korzeniak U. 2002. Ekologiczne liczby wskaźnikowe roślin naczyniowych Polski. s. 183. Instytut Botaniki im. W. Szafera, Polska Akademia Nauk, Kraków.

Łukasz MaćKowiak, Kowalewo 6, 64-061 Kamieniec, Polska; e-mail: lukaszmackowiak123@ gmail.com

Wptynęto: 24.05.2020 r.; przyjęto do druku: 17.12.2020 r.

DOI: https://doi.org/10.35535/ffgp-2020-0057

\title{
Nowe stanowiska Luronium natans (Alismataceae) w Polsce
}

Luronium natans (L.) Raf. (elisma wodna) jest europejskim endemitem obejmującym zasięgiem północno-zachodnią, zachodnią oraz środkowowschodnią część kontynentu. Liczne stanowiska są rozmieszczone na Wyspach Brytyjskich oraz w Europie Środkowej (SzMEJA 2014). Sporadycznie gatunek jest notowany na Półwyspie Skandynawskim oraz w Danii (LANSDOWN 2013).

W Polsce Luronium natans występuje głównie na obszarze Pojezierzy Wschodniopomorskiego, Południowopomorskiego i Zachodniopomorskiego oraz na Pobrzeżu Koszalińskim i Szczecińskim. Ponadto, gatunek stwierdzono w rejonie Nysy Łużyckiej na stanowisku Potok (RosAdZIŃSKi 2014). Populacja pomorska występuje w jeziorach oligotroficznych i mezotroficznych, od miękkowodnych do umiarkowanie zasobnych w wapń. Elisma wodna rośnie w nich na głębokości od 0 do 2,0 m, najczęściej w płatach zbiorowisk roślinnych z klasy Littorelletea uniflorae Br.-Bl. et R.Tx. 1943 oraz w zbiorowiskach wodnych mszaków: Sphagnum denticulatum Brid. i Warnstorfia exannulata (Schimp.) Loeske (CHMARA i in. 2015). Luronium natans tworzy też własne zbiorowisko: Luronietum natantis Szańkowski ex Šumberová, Čtvrtlíková et Bauer (ŠUmBERová $\mathrm{i}$ in. 2011). 
Luronium natans jest zimozieloną rośliną wodną, należącą do isoetidów. Rzadziej spotykane są formy wodno-lądowe. Wytwarza dwa typy liści (różnolistność) - liście pływające po powierzchni wody i liście podwodne (HyLDGAARD \& BRIX 2011; CHMARA i in. 2019). Dojrzały osobnik podwodny, o wzroście klonalnym, składa się z kilku rozet liści, połączonych cienkimi rozłogami (SzMEJA 2014). Liście tworzące rozety u form podwodnych są jasnozielone i równowąskie (wstęgowate). Forma wodno-lądowa nie wytwarza rozety liściowej (o typowych liściach wstęgowatych), lecz tworzą się liście pływające, eliptyczne i skórzaste, opatrzone długim ogonkiem liściowym.

Luronium natans według Polskiej czerwonej listy paprotników i roślin kwiatowych (KAŹMIERZCZAKOWA i in. 2016) jest gatunkiem zagrożonym (EN) w Polsce, natomiast na świecie i w Europie określony został jako takson najmniejszej uwagi (LC). Ponadto, gatunek objęty jest Konwencją Berneńską i wymieniony w Załączniku Nr II Dyrektywy Siedliskowej numer 92/43/EEC (DYREKTYwA RADY 1992), kod gatunku 1831. W Polsce roślina podlega ochronie ścisłej (RozPORZĄDZENIE 2014).

W sezonach wegetacyjnych w 2017 r. i 2019 r. stwierdzono dwa, dotychczas nie notowane w Polsce stanowiska Luronium natans - w jeziorze Lubowisko i jeziorze Pijawka (Ryc. 1). Jezioro Lubowisko według aktualnej regionalizacji fizyczno-geograficznej Polski (Solon i in. 2018) jest położone w mezoregionie Pojezierza Kaszubskiego, natomiast jezioro Pijawka zlokalizowane jest w mezoregionie Pojezierza Krajeńskiego. Jezioro Lubowisko położone jest w zlewni leśnej w obrębie Rynny Gołubieńsko-Ręboszewskiej, zbiornik łączy się poprzez wąski przesmyk z Jeziorem Dąbrowskim. Powierzchnia jeziora Lubowisko wynosi 36 ha, a głębokość maksymalna to 7,6 m (CHOIŃsKi 1991). Według

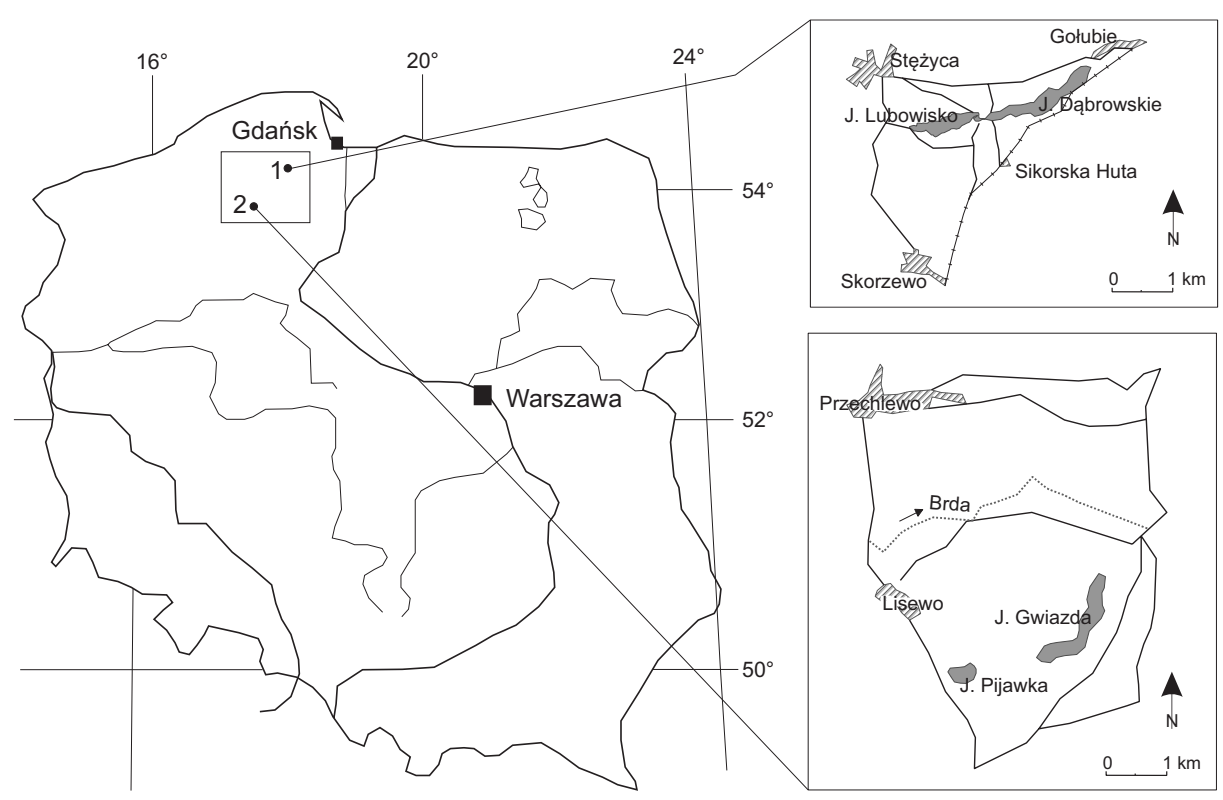

Ryc. 1. Lokalizacja nowych stanowisk Luronium natans $(1,2)$ w Polsce

Fig. 1. New localities of Luronium natans $(1,2)$ in Poland 
badań własnych autorów wykonanych w maju 2020 r., woda w tym jeziorze odznacza się umiarkowaną przezroczystością (widzialność krążka Secchiego 3,0 m) i jest prawie

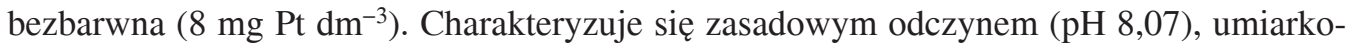
waną zasobnością w sole mineralne (przewodnictwo elektrolityczne $190 \mu \mathrm{S} \mathrm{cm}^{-1}$ ) oraz podwyższonym stężeniem wapnia $39,8 \mathrm{mg} \mathrm{Ca} \mathrm{dm}^{-3}$. Jezioro Pijawka ma powierzchnię 3,8 ha (CHoiński 1991), głębokość maksymalna wynosi 7,0 m. W zlewni bezpośredniej dominują lasy mieszane i bory świeże, na wschodnim brzegu występuje płat boru bagiennego. Woda powierzchniowa w jeziorze charakteryzuje się niedużą przezroczystością (widzialność krążka Secchiego do 2,0 m), umiarkowanym zabarwieniem (24 mg Pt dm ${ }^{-3}$ ), kwaśnym

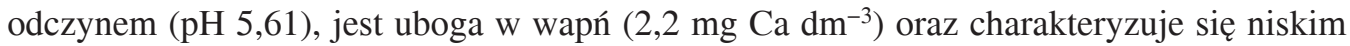
przewodnictwem elektrolitycznym $\left(25 \mu \mathrm{S} \mathrm{cm}^{-1}\right.$; badania własne autorów).

W jeziorze Lubowisko odnaleziono dwa niewielkie skupiska Luronium natans, przy północnym brzegu jeziora, na głębokości ok. 0,5-0,6 m. Powierzchnia obu skupisk wynosiła ok. $0,25 \mathrm{~m}^{2}$. Osobniki występowały na podłożu mineralnym. Zanotowano zarówno osobniki maturalne wytwarzające liście nawodne i kwiaty oraz osobniki podwodne, w formie rozety liści. Na obu stanowiskach przeprowadzono badania struktury ilościowej gatunków:

1. Data: 10.08 .2017 , lokalizacja: $54^{\circ} 11^{\prime} 55,4^{\prime \prime} \mathrm{N}, 17^{\circ} 58^{\prime} 52,3^{\prime \prime} \mathrm{E}$ (ATPOL: CB 0643), powierzchnia: 2,25 m², głębokość 0,5 m, dno piaszczyste, pokrycie warstwy 50\%: Chara virgata 3, Luronium natans 2, Potamogeton natans 2, Eleocharis palustris 1, Potamogeton obtusifolius + , Elodea canadensis + .

W jeziorze Pijawka stwierdzono obfite występowanie Luronium natans. Osobniki tego gatunku tworzą rozległe płaty wzdłuż północnego i wschodniego brzegu jeziora. Zaobserwowano zarówno okazy kwitnące o liściach nadwodnych jak i te wytwarzające podwodne rozety liściowe (Ryc. 2).

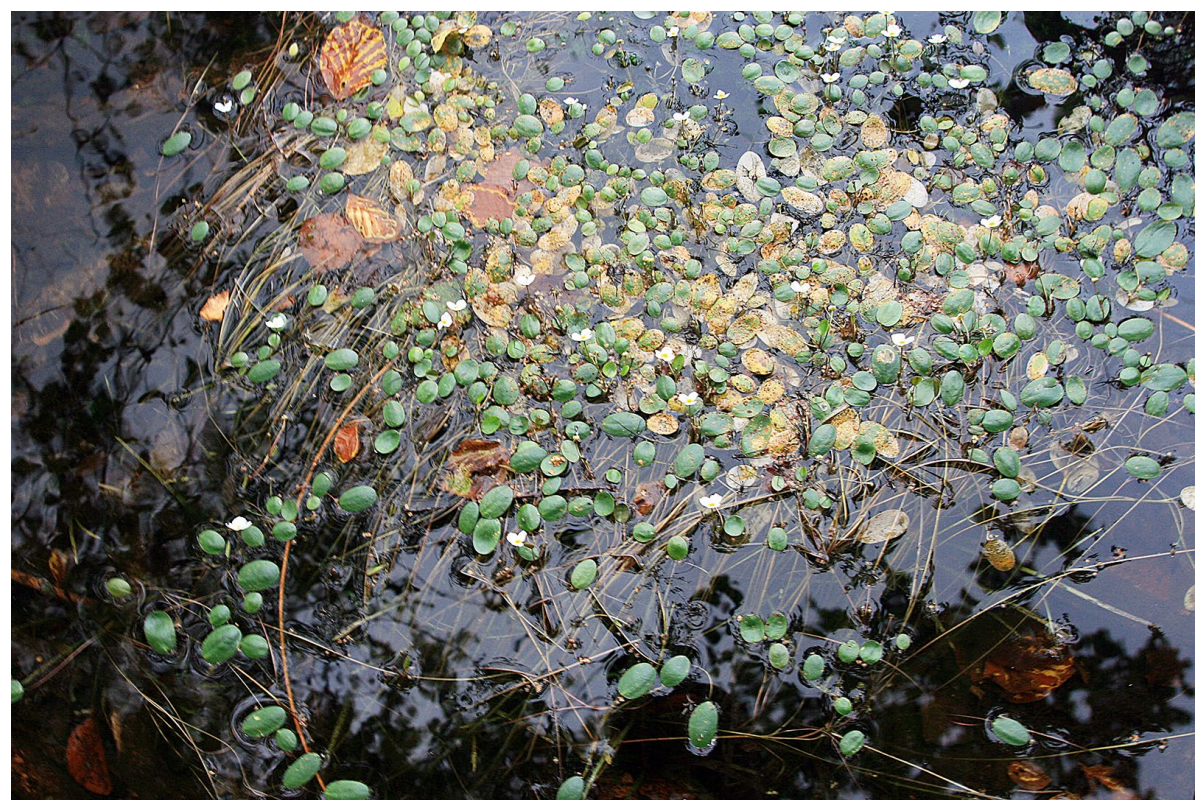

Ryc. 2. Kwitnące osobniki Luronium natans na nowym stanowisku w jeziorze Pijawka (fot. E. Rekowska, 22.08.2019 r.)

Fig. 2. Flowering individuals of Luronium natans at the new locality in Lake Pijawka (photo by E. Rekowska, 22.08.2019) 
2. Data: 22.08.2019, lokalizacja: $53^{\circ} 45^{\prime} 23,1^{\prime \prime} \mathrm{N}, 1^{\circ} 16^{\prime} 59,1^{\prime \prime} \mathrm{E}$ (ATPOL: CB 5127), powierzchnia: 2,25 m², głębokość 0,3 m, dno piaszczyste, pokrycie 85\%: Warnstorfia exannulata 3, Luronium natans 3, Sphagnum denticulatum 1 .

3. Data: 22.08 .2019 , lokalizacja: $53^{\circ} 45^{\prime} 20,8^{\prime \prime} \mathrm{N}, 17^{\circ} 16^{\prime} 50,0^{\prime \prime} \mathrm{E}$ (ATPOL: CB 5127), powierzchnia: 2,25 m², głębokość 0,4 m, dno organiczne, pokrycie 90\%: Luronium natans 4, Carex rostrata 3, Persicaria amphibia 2, Warnstorfia exannulata 2, Sphagnum denticulatum 1.

Jezioro Lubowisko podlega umiarkowanej presji człowieka. Często jest odwiedzane przez turystów i wędkarzy. Na północnym brzegu znajduje się stanica harcerska z trwałą zabudową i pomostem, a na zachodnim brzegu jeziora kąpielisko. Elisma wodna zajmuje niewielką powierzchnię fitolitoralu jeziora. Głównym rodzajem presji na jezioro Pijawka jest wędkarstwo i użytkowanie rybackie. W przeszłości jezioro było intensywnie użytkowane wędkarsko i rybacko. Populacja elismy wodnej jest bardzo liczna i dobrze zachowana.

Odnalezienie dwóch nowych stanowisk wzbogaca wiedzę o występowaniu rzadkiego endemitu w Polsce i stanowi podstawę do ewentualnych działań ochronnych. Biorąc pod uwagę wykaz ostoi Luronium natans w Polsce według BAZYDŁo (2005) oraz notowanie z Potoku (RosAdZIŃski 2014), w Polsce zanotowano 64 stanowiska tego gatunku. Po uwzględnieniu dwóch nowych lokalizacji, L. natans występuje na 66 stanowiskach w Polsce.

Summary. New stations of Luronium natans (Alismataceae) in Poland. Luronium natans (L.) Raf. is a very rare species in Europe. New stations of L. natans were found in the Pomeranian Lakeland (NW Poland) in 2017 and 2019: Lake Lubowisko - ATPOL square CB 0643; and Lake Pijawka - ATPOL square CB 5127. In lake Lubowisko it was found at 0.5-0.6 m depth (water $\mathrm{pH} 8.07$, conductivity 190 $\mu \mathrm{S} \mathrm{cm} \mathrm{cm}^{-1}$, calcium concentration $39.8 \mathrm{mg} \mathrm{Ca} \mathrm{dm}^{-3}$ ). In lake Pijawka, L. natans occupied the northern and eastern shores. The water is acidic and poor in dissolved salts, including calcium salts. In lake Pijawka the plants occur together with mosses (Warnstorfia exannulata, Sphagnum denticulatum).

\section{LITERATURA}

BAZYDŁo E. 2005. Biologia i ekologia populacji Luronium natans (L.) Rafin. Mskr. rozprawy doktorskiej, Wydział Biologii Uniwersytetu Gdańskiego, Gdańsk.

ChMara R., BAnaś K. \& SzMEja J. 2015. Changes in the structural and functional diversity of macrophyte communities along an acidity gradient in softwater lakes. - Flora 216: 57-64.

ChMARA R., Szmeja J. \& RobioneK A. 2019. Leaf traits of macrophytes in lakes: interspecific, plant group and community patterns. - Limnologica 77. https://doi.org/10.1016/j.limno.2019.125691.

CholŃski A. 1992. Katalog jezior Polski. Pojezierze Pomorskie. s. 221. Wydawnictwo Naukowe Uniwersytetu im. Adama Mickiewicza, Poznań.

DYREKTYWA RADY 92/43/EWG z dnia 21 maja 1992 r. w sprawie ochrony siedlisk przyrodniczych oraz dzikiej fauny i flory. Dz.U. L 206, 22.07.1992 P. 0007-0050, zmieniona Dyrektywa 97/62/EWG z dnia 27 października $1997 \mathrm{r}$.

HYLDGAARD B. \& BRIX H. 2011. Plasticity in carbon acquisition of the heterophyllous Luronium natans: an endangered freshwater species in Europe. - Aquatic Botany 94: 127-133.

Kaźmierczakowa R., Bloch-OrŁowska J., Celka Z., Cwener A., Dajdok Z., Michalska-Hejduk D., PAWLIKOWSKI P., SZCZÉśniaK E. \& ZIARNeK K. 2016. Polska czerwona lista paprotników i roślin kwiatowych. s. 44. Instytut Ochrony Przyrody Polskiej Akademii Nauk, Kraków. 
LANSDOWN R.V.2013.Luroniumnatans. The IUCNRedList of threatened species 2013:e.T162134A5547543. http://dx.doi.org/10.2305/IUCN.UK.2011-1.RLTS.T162134A5547543.en (dostęp: 13.11.2019).

RoSADZIŃSKI S. 2014. Raport z monitoringu gatunków i siedlisk przyrodniczych prowadzonego w latach 2013-2014. Generalny Inspektorat Ochrony Środowiska. http://siedliska.gios.gov.pl/images /pliki_pdf/ wyniki/2013-2014/dla_roslin/Elisma-wodna-Luronium-natans.pdf (dostęp: 03.12.2019).

RozPORZĄDZENIE Ministra Środowiska z dnia 9 października 2014 r. w sprawie ochrony gatunkowej roślin (Dz. U. 2014, poz. 1409).

Solon J., Borzyszkowski J., BidŁasik M., Richling A., Badora K., Balon J., Brzezińska-Wójcik T., Chabudziński Ł., Dobrowolski R., Grzegorczyk I., JodŁowski M., Kistowski M., Kot R., Krąż P., Lechnio J., Macias A., Majchrowska A., Malinowska E., Migoń P., Myga-Piątek U., Nita J., Papińska E., RodZik J., StrzyŻ M., TerpiŁowski S. \& Ziaja W. 2018. Physico-geographical mesoregions of Poland: verification and adjustment of boundaries on the basis of contemporary spatial data. - Geographia Polonica 91: 143-170.

ŠUmberová K., ČTVRTLíKOVÁ M. \& BAUER P. 2011. VDB05 Luronietum natantis Szańkowski ex Šumberová, Čtvrtlíková et Bauer. - W: M. CHYTRÝ (red.), Vegetace České republiky. 3. Vodní a mokřadní vegetace [Vegetation of the Czech Republic. 3. Aquatic and wetland vegetation], s. 296-299. Academia, Praha.

SzMEJA J. 2014. Luronium natans (L.) Raf. Elisma wodna. - W: R. KAŹMiercZAKowa, K. ZARZYCKI \& Z. MiRek (red.), Polska czerwona księga roślin, s. 556-557. Instytut Ochrony Przyrody, Polska Akademia Nauk, Kraków.

RafaŁ Chmara i Emilia ReKowska, Katedra Ekologii Roślin Uniwersytetu Gdańskiego, ul. Wita Stwosza 59, 80-308 Gdańsk, Polska; e-mail: rafal.chmara@.ug.edu.pl

Wptynęto: 29.01.2020 r.; przyjęto do druku: 24.11.2020 r.

DOI: https://doi.org/10.35535/ffgp-2020-0058

\section{Nowe stanowisko Bromus secalinus (Poaceae) w Polsce środkowej}

Rodzaj Bromus L. (stokłosa) obejmuje około 150 gatunków z rodziny Poaceae, rozpowszechnionych w biomach klimatu umiarkowanego półkuli północnej, jak również w wyższych pasmach górskich strefy międzyzwrotnikowej (FEDOROV 1974; HulteN \& FRIES 1986).

Gatunkiem typowym jest Bromus secalinus L. (stokłosa żytnia), znany też pod wieloma nazwami ludowymi, np. kostrzeba, kłosówka polna czy stokłosa kostrzewa. Jest to jednoroczna (sporadycznie dwuletnia), ozima, rzadziej jara, kępkowa trawa o prostych wzniesionych źdźbłach, podzielonych na 5-7 międzywęźli. Charakteryzuje się nagimi, rzadko tylko słabo owłosionymi pochwami liściowymi, luźno owłosionymi blaszkami liści oraz kwiatostanem, a następnie owocostanem w formie wielostronnej wiechy o szorstkich gałązkach. Najdłuższe z nich kończą się 3-5 kłoskami, krótsze jednym lub dwoma. Kłosek pod względem wielkości przypomina nieco pojedynczy ziarniak żyta. Przed kwitnięciem wiecha wznosi się, po zapyleniu luźno zwisa. Jeden osobnik zawiązuje około 1300-1500 podłużnych, brązowych ziarniaków, przyrośniętych do plewki górnej (FALKOwsKi 1982; NowAK \& NowAK 2006). 